\title{
Selective prosecution of scientists must stop
}

\author{
The US Department of Justice's 'China Initiative' is unfairly targeting Chinese American academics for their alleged \\ ties with the Chinese government. A more proportionate approach is urgently needed.
}

A lthough the rising geopolitical tensions between the United States and China have been making headlines for a number of years, their troubling effect on US-based scientists working between both countries has received comparatively less scrutiny.

The arrest of MIT professor Gang Chen earlier this year, for allegedly failing to report his ties to the Chinese government in federal grant applications, is therefore a sobering reminder of the drastic consequences for individuals caught in the cross-hairs of the US Department of Justice (DOJ) as it prioritizes cases related to economic espionage and trade secret theft on the part of the Chinese state, a mandate it refers to as the 'China Initiative'.

Shocked by the heavy-handed manner in which criminal proceedings were launched against him, Chen's colleagues - and MIT, which is paying for his legal fees - have jumped to his defence. In a letter of support written by about 170 members of the MIT faculty, they point out how the official complaint against Chen is "filled with allegations and innuendo based on what are, in fact, some of the most routine and even innocuous elements of our professional lives," and "portrayed as some sort of collusion with outside forces in an effort to help them steal American technology".

Chen's case is, sadly, not an isolated one: last year the federal government charged Harvard professor Charles Lieber for alleged undisclosed ties with China, and there are a number of other similar cases at the universities of Kansas, Tennessee and Texas A\&M. While these cases differ in their details, they all allege false statements or 'grant fraud' on behalf of the defendants. None allege actual intellectual property theft, however.

A powerful testimony of the harrowing experience of being wrongfully accused of scientific espionage comes from Xiaoxing $\mathrm{Xi}$, the former Chair of the Department of Physics at Temple University in Philadelphia, and this year's recipient of the American Physical Society's Andrei Sakharov Prize. In 2015, Xi was arrested at gunpoint in front of his family and charged with relaying the blueprints for a laboratory device known as a pocket heater to colleagues in China. The case collapsed a few months later, after leading physicists testified that the blueprints at the heart of the case were for a completely different device that Xi was describing as part of normal academic collaboration. But this was not before he was suspended from his job, prohibited from entering campus or speaking with students, and put under financial duress to cover his legal costs.

\section{"The actions of the DOJ ultimately undermine US leadership in science and technology."}

$\mathrm{Xi}$ is now committed to sharing his experience so that he can provide insights into the challenges Chinese scientists face as a result of the DOJ's China Initiative, and raise awareness of the threat it represents to the open environment in fundamental research in the United States. In his talk at the American Physical Society March Meeting, he outlined three main lessons that he has learned from his ordeal: first, what the DOJ alleges in its indictments is not necessarily true - there appears to be a pattern of misrepresenting information and sensationalizing it for the press. Second, argues Xi, Chinese American scientists seem to be unfairly targeted by these investigations. And third, he says, the DOJ is effectively criminalizing academic collaborations with China, with one lead prosecutor publicly stating that such activity is "by definition conveying sensitive information to the Chinese".

$\mathrm{Xi}$ is surely not alone in seeing the parallels between this arbitrary use of 'guilt by association' arguments and the Red Scare that took hold at the height of the Cold War and became synonymous with its most avid supporter, Senator Joseph McCarthy. But thankfully, Xi also points out that there is already a template for protecting the US fundamental research enterprise against foreign influence - Chinese or otherwise and it comes in the form of an authoritative report (https://go.nature.com/3cZCE9j) prepared by the elite science advisory group known as JASON and endorsed by the National Science Foundation in 2019.

The JASON report makes it clear that foreign influence through rewards, deception, coercion and theft are a real and growing threat to US research. Yet it also concludes that these problems can be addressed within the framework of research integrity. In particular, failure to disclose possible conflicts of interest should first be investigated by universities and funding agencies and treated in a manner akin to scientific misconduct. Of course, wilfully supplying incorrect information as part of a disclosure can still result in legal consequences, but honest mistakes or oversights can and should be handled in a proportionate manner, especially when it is not always made clear what should be reported.

While the framework proposed by JASON is largely nation agnostic, it acknowledges that recent concerns have focused on the actions of China. Nevertheless, it also emphasizes the importance of judging individuals on personal actions and not by profiling them based on the actions of the government and political institutions of their home country. Ultimately, this is what is so troubling about the China Initiative: it singles out scientists, effectively for conducting research while being Chinese. It is simply intolerable.

Xi's wider point is that the actions of the DOJ ultimately undermine US leadership in science and technology. There is a long-standing and well-established distinction drawn between fundamental and classified research. Short of pursuing a policy of complete academic decoupling from China, blurring the lines between these two modes of operation risks putting far too many innocent researchers in harm's way. $\mathrm{He}$ is surely right to urge the US scientific community to rally around the JASON report, and speak up to defend Chinese colleagues against injustice, safeguard open fundamental research on university campuses and protect US leadership in science and technology.

Published online: 9 April 2021 https://doi.org/10.1038/s41567-021-01231-1 